\title{
Reductive Electrophotocatalysis: Merging Electricity and Light to Achieve Extreme Reduction Potentials
}

Hyunwoo Kim, Hyungjun Kim, Tristan Lambert, Song Lin

Submitted date: 08/10/2019 - Posted date: 08/10/2019

Licence: CC BY-NC-ND 4.0

Citation information: Kim, Hyunwoo; Kim, Hyungjun; Lambert, Tristan; Lin, Song (2019): Reductive Electrophotocatalysis: Merging Electricity and Light to Achieve Extreme Reduction Potentials. ChemRxiv. Preprint.

We describe a new electrophotocatalytic strategy that harnesses the power of light and electricity to generate an excited radical anion with a reducing potential of $-3.2 \mathrm{~V}$ vs. SCE, which can be used to activate substrates with very high reduction potentials $\left(\mathrm{E}_{\text {red }} \sim-1.9\right.$ to $\left.-2.9 \mathrm{~V}\right)$. The resultant aryl radicals can be engaged in various synthetically useful transformations to furnish arylboronate, arylstannane, and biaryl products.

File list (2)

TOC.pdf (710.66 KiB) view on ChemRxiv - download file 


\title{
Reductive Electrophotocatalysis: Merging Electricity and Light to Achieve Extreme Reduction Potentials
}

\author{
Hyunwoo $\mathrm{Kim}^{\dagger}$, Hyungjun $\mathrm{Kim}^{\ddagger}$, Tristan H. Lambert*†, and Song Lin*† \\ 'Department of Chemistry and Chemical Biology, Cornell University, Ithaca, New York 14853, United States \\ \#Department of Chemistry, Incheon National University, 119 Academy-ro, Yeonsu-gu, Incheon 22012, Republic of Korea
}

\begin{abstract}
We describe a new electrophotocatalytic strategy that harnesses the power of light and electricity to generate an excited radical anion with a reducing potential of $-3.2 \mathrm{~V}$ vs. SCE, which can be used to activate substrates with very high reduction potentials $\left(E_{\text {red }} \sim-1.9\right.$ to $\left.-2.9 \mathrm{~V}\right)$. The resultant aryl radicals can be engaged in various synthetically useful transformations to furnish arylboronate, arylstannane, and biaryl products.
\end{abstract}

Due to the unique reactivity of open-shell intermediates, the development of catalytic transformations driven by single-electron transfer (SET) has been an area of intense research in organic chemistry. ${ }^{1}$ In particular, the employment of unconventional means of activation, including photoredox catalysis ${ }^{2}$ and electrocatalysis, ${ }^{3}$ has provided unique entry to single-electron reactivities and led to new solutions to challenging synthetic problems that are not readily addressed using existing tools. In the realm of redox organic reactions, both photoredox catalysis and electrochemistry have been successfully applied to a diverse suite of oxidative transformations. However, reductive transformations, particularly those that require highly reducing potentials, remain an underdeveloped area for both of these reaction strategies. ${ }^{2 b, 3 a}$ In principle, electrochemistry can grant access to extreme reducing potentials, and significant contributions in this regard have recently been made. ${ }^{4}$ Nevertheless, the constant application of such highly biased potentials can lead to uncontrolled reactions due to accumulation of reactive intermediates near the electrode surface as well as compromised chemoselectivity in complex reaction systems. Thus, the development of catalytic strategies that are both highly reducing and also chemoselective remains a major challenge.

To this end, we envisioned a new electrophotocatalytic strategy that merged the power of electrical and photochemical energy ${ }^{5}$ to realize extremely high reduction potentials under catalyst control. One of our groups (T.H.L.) recently described an oxidative electrophotocatalytic system that achieved an extremely high oxidation potential ( $3.33 \mathrm{~V}$ vs. SCE) ${ }^{6}$ This high oxidizing power resulted from the photoexcitation of an open-shell, radical cation intermediate that was generated by electrochemical means. We reasoned that a similar potency should be achievable for reductive chemistry through the generation and photoexcitation of a radical anion intermediate. Indeed, the strongly reducing character of radical anions has long been known. ${ }^{7}$ Recently, König has described systems that undergo sequential photo-induced reduction to form radical anions followed by a second photoexcitation of the resulting radical anions. ${ }^{8}$ Such a strategy, however, requires that the same catalyst must serve as both a photooxidant and, once reduced, a photoreductant. In addition, the photooxidation step can be problematic in that it necessitates the formation of oxidative byproducts (e.g. $\mathrm{Et}_{3} \mathrm{~N}^{\cdot+}$ ), which limits the effective reducing power of the system due to back electron transfer or competing side reactions. ${ }^{2 b}$
Scheme 1. Reductive electrophotocatalysis for the functionalization of aryl halides

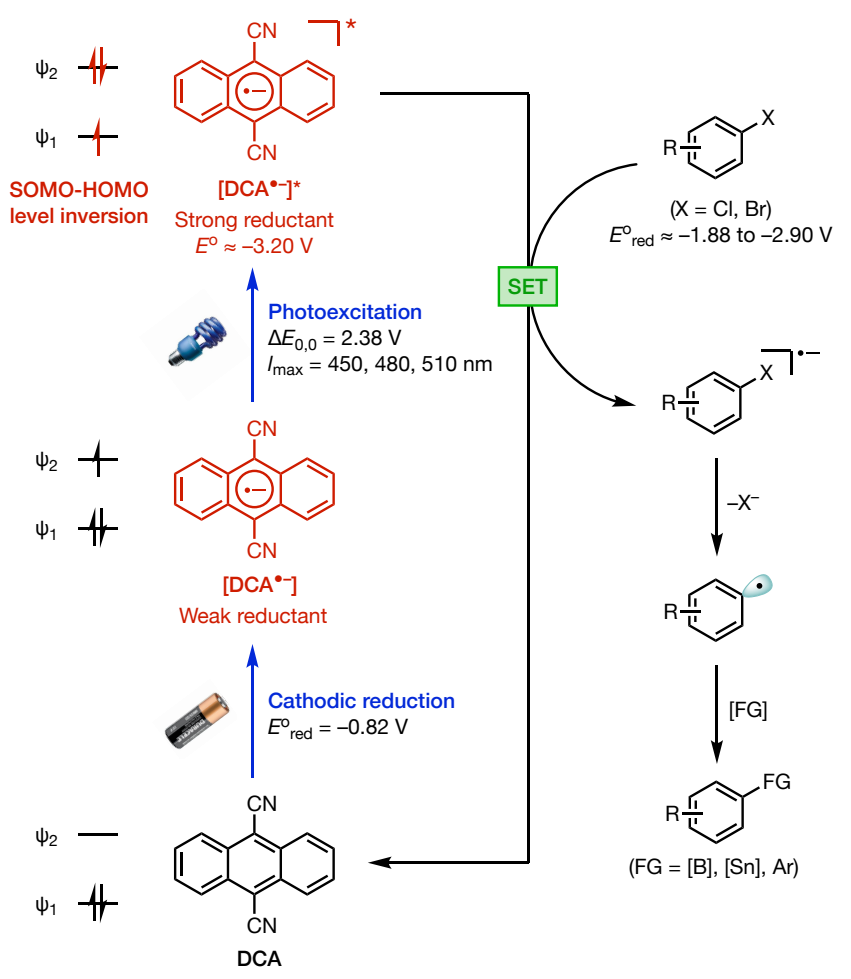

We propose a new electrophotocatalytic strategy to access extremely reducing intermediates via tandem cathodic reduction and photoexcitation. The use of electrochemistry circumvents the photooxidation step in the consecutive dual photoredox approach, because the catalyst radical anion can be generated from the neutral precursor without the need for a chemical reductant. For example, cathodic reduction of dicyanoanthracene (DCA; $\left.E_{1 / 2}=-0.82 \mathrm{~V}\right)$ results in the corresponding radical anion $\mathrm{DCA}^{-}$, which absorbs visible light and exhibits a strong fluorescence emission (excitation energy $\left.E_{0,0}=2.38 \mathrm{eV}\right) .{ }^{9}$ The photoexcited DCA $\left(\mathrm{DCA}^{-*}\right)$ is estimated to display an exceptionally high reducing potential of -3.2 $\mathrm{V}$ (vs. SCE), ${ }^{10}$ which TD-DFT calculations suggest arises from a SOMO-HOMO level inversion featuring a very unstable electronic structure with a half-filled bonding orbital $\left(\psi_{1}\right)$ and a filled antibonding orbital $\left(\psi_{2}\right)$. This value is on par with some of the most reducing elemental metals such as $\operatorname{Li}(E=-3.3 \mathrm{~V})$. Importantly, however, the tandem electrochemical activation and photoexcitation allows the formation of this highly reducing catalyst in a very low concentration in a controllable fashion, thus providing an avenue to circumvent the chemoselectivity issues frequently associated with deep reductive chemistry using chemical reductants or direct 
electrolysis. In this Communication, we apply this electrophotocatalytic strategy to the reductive functionalization of a wide range of aryl halides with reduction potentials $\left(E_{\text {red }}\right)$ as low as $-2.94 \mathrm{~V}$.

As a proof of concept, we first confirmed that $\mathrm{DCA}^{--}$can be generated and is stable under preparative electrochemical conditions (Figure 1). Using a porous carbon cathode and a zinc plate sacrificial anode in an H-type divided cell, the application of a constant cell voltage of $3.2 \mathrm{~V}$ (corresponding to a cathodic potential of -1.0 $\mathrm{V}$ vs SCE) resulted in the formation of a deep orange solution in the cathodic compartment. The UV-vis absorption spectrum of this solution is identical to that of $\mathrm{DCA}^{-}$- reported in the literature. ${ }^{9}$

Figure 1. Electrochemical Generation of Radical Anion
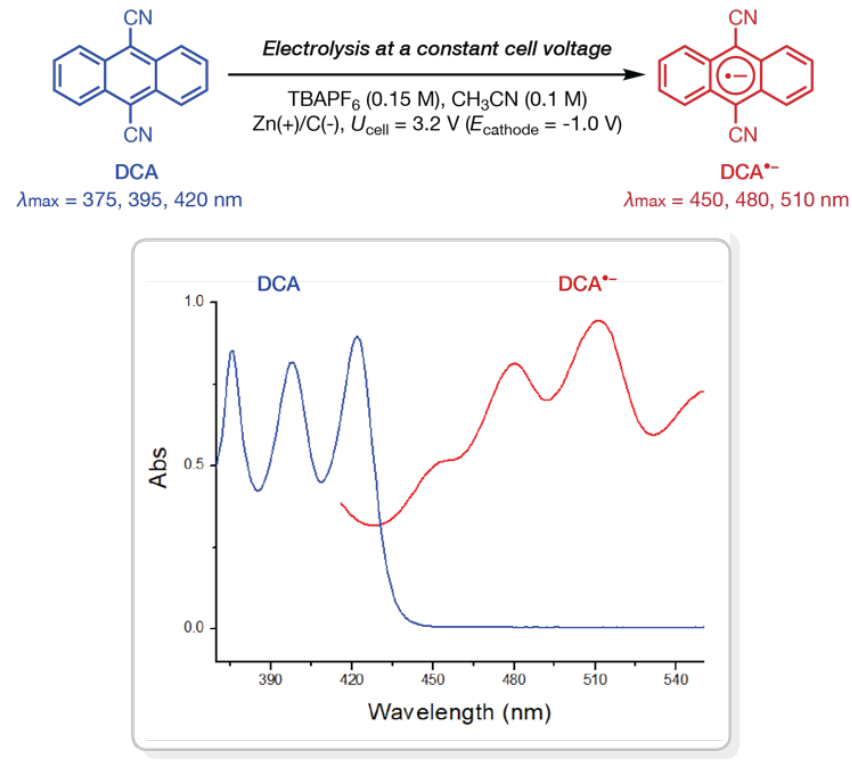

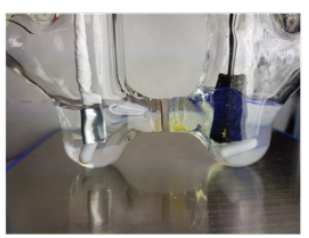

before electrolysis (DCA)

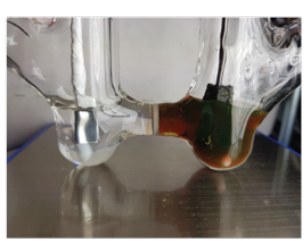

after electrolysis $\left(\mathrm{DCA}^{\circ}\right)$
We next set out to investigate our proposed electrophotocatalytic system in the context of the reductive functionalization of aryl halides. In recent years, the generation of aryl radicals from aryl halides has been shown to be a productive synthetic strategy. ${ }^{11}$ However, current methods are largely limited to substrates with relatively labile carbon-halogen bonds or low reduction potentials. ${ }^{8,11}$ For example, aryl chlorides often display high reduction potentials $(>-2.0 \mathrm{~V})$ and strong bond dissociation energies $(>97 \mathrm{kcal} / \mathrm{mol}),{ }^{12}$ and thus can be difficult to engage in reductive reactions in the single-electron manifold. In addition, electron-rich aryl halides are often recalcitrant to single electron reductions. Here, we show that reductive electrophotocatalysis allows for the engagement of these challenging substrates.

We chose to study the borodechlorination of ethyl 4-chlorobenzoate $\left(1, E_{\text {red }}=-2.04 \mathrm{~V} \text { vs SCE }\right)^{12}$ using DCA as the catalyst and bis(pinacolato)diboron $\left(\mathrm{B}_{2} \mathrm{pin}_{2}\right)$ as the radical acceptor (Table 1). To date, only a few examples are available for the borylation of aryl chlorides under metal-free conditions. ${ }^{13}$ After optimization, we observed that the application of both blue light and current enabled efficient coupling of $\mathbf{1}$ and $\mathrm{B}_{2}$ pin $_{2}$ to furnish arylboronate $\mathbf{2}$ in $88 \%$ yield (entry 1). The optimal conditions employed pyridine (20 $\mathrm{mol} \%$ ) as an additive, $\mathrm{TBAPF}_{6}$ as the electrolyte, carbon foam and zinc plate as cathode and anode, respectively, in $\mathrm{MeCN}$ with an applied cell voltage of $3.2 \mathrm{~V}$ under blue LED irradiation. A set of control experiments revealed that current, light, and DCA are all necessary for reactivity (entries 2-4). Pyridine, which is known to coordinate to $\mathrm{B}_{2} \mathrm{pin}_{2}$ and promote the formation of a $\mathrm{B}$-centered persistent radical intermediate, ${ }^{13 a}, 14$ was beneficial to reaction efficiency (entry 5).

Table 1. Reaction Optimization ${ }^{a}$

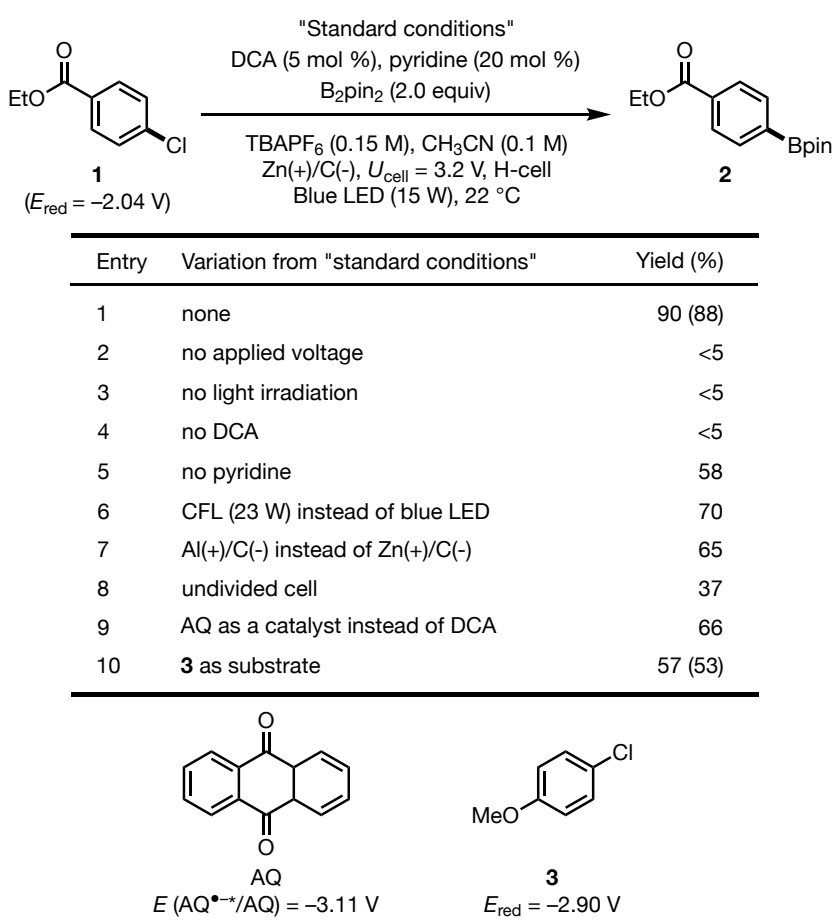

${ }^{a}$ Cathodic chamber: 1 (0.4 mmol, 1.0 equiv), DCA (5 mol \%), B ${ }_{2}$ pin $_{2}(2.0$ equiv), pyridine $(20 \mathrm{~mol} \%), \mathrm{TBAPF}_{6}(0.15 \mathrm{M}), \mathrm{CH}_{3} \mathrm{CN}(0.1 \mathrm{M})$; anodic chamber: $\operatorname{TBAPF}_{6}(0.15 \mathrm{M}), \mathrm{CH}_{3} \mathrm{CN}(0.1 \mathrm{M})$; cell voltage $\left(U_{\text {cell }}\right)=3.2 \mathrm{~V}$; yields determined by ${ }^{1} \mathrm{H}$ NMR (isolated yield in parentheses).

We found that the use of white CFL was also productive (entry 6), albeit with slightly reduced efficiency relative to the blue LEDs. Changing the sacrificial anode from $\mathrm{Zn}$ to $\mathrm{Al}$ did not significantly affect the reaction yield (entry 7). The reaction, in principle, can be conducted in an undivided cell, which indeed provided the desired product in $37 \%$ yield. However, the reaction was prematurely terminated due to the formation of a zinc bridge between the cathode and anode that short-circuited the electrochemical setup (entry 8). Anthraquinone (AQ), which exhibits similar light-induced redox reactivities, ${ }^{9}$ was also an effective catalyst, albeit with diminished yield (entry 9). Importantly, this reaction was also applicable to the reductive borylation of 4-chloroanisole (3), which has a highly negative reduction potential $\left(E_{\text {red }}=-2.90 \mathrm{~V} \text { vs SCE }\right)^{15}$ (entry 10$)$. This result highlights the extreme reducing power that this catalytic system can provide. Notably, this substrate has not been successfully engaged in high yielding reductive functionalizations using photoredox catalysis. 
Table 2. Scope of Electrophotocatalytic Borylation ${ }^{a}$
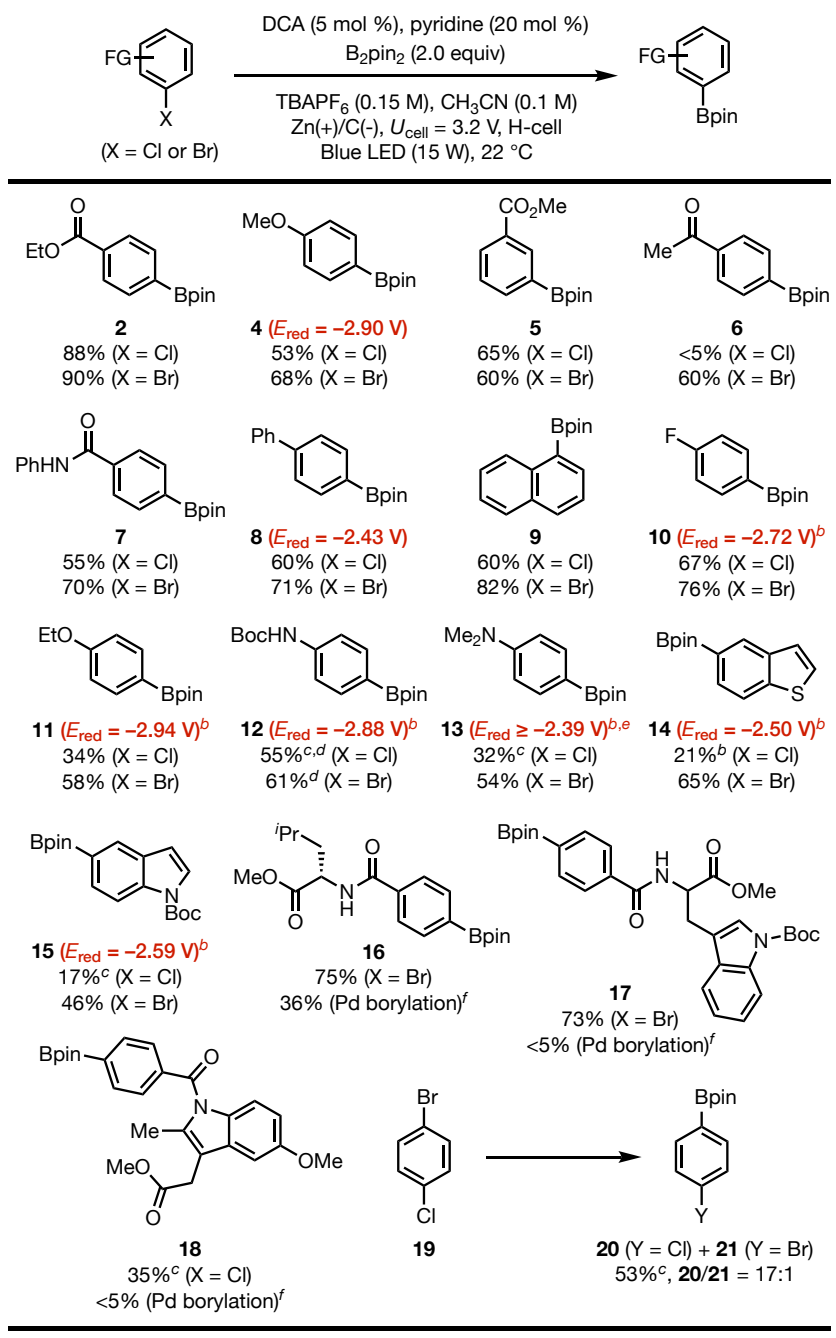

Isolated yields are reported. ${ }^{a}$ Optimal conditions from Table 1 used. ${ }^{b} \mathrm{Cal}-$ culated $E_{\text {red }}$ values. ${ }^{c} 10 \mathrm{~mol} \%$ DCA. ${ }^{d}$ Yield determined by ${ }^{1} \mathrm{H}$ NMR. ${ }^{e} E_{\text {red }}$ could not be accurately determined. ${ }^{f}$ Aryl halide $(0.25 \mathrm{mmol}, 1$ equiv), $\mathrm{Pd}(\mathrm{dppf}) \mathrm{Cl}_{2}(5 \mathrm{~mol} \%), \mathrm{KOAc}$ (3.0 equiv), $\mathrm{B}_{2} \mathrm{pin}_{2}$ (1.2 equiv) in DMSO $(0.85 \mathrm{~mL})$ under $110^{\circ} \mathrm{C}$ for $12 \mathrm{~h}$.

We have found that this reaction is capable of borylating a wide range of aryl halides. A number of functional groups potentially sensitive to strongly reducing conditions, such as ester ( $\mathbf{2}$ and $\mathbf{5}$ ), ketone (6), amide and carbamate (7 and 12), thiophene (14), and $N$ Boc indole ${ }^{16}(\mathbf{1 5})$ groups were well tolerated. These results showcase that, although our catalytic strategy grants access to extremely reducing potentials, it does so under catalyst control with a high level of chemoselectivity that is typically uncommon in deep reductive reactions promoted by reducing metals. In principle, the same types of products could be obtained using Pd-catalyzed borylation. Nevertheless, this metal-catalyzed method ${ }^{17}$ provided substantially lower yield for substrates bearing multiple Lewis basic coordinating groups (e.g. 16-18) ${ }^{18}$ When applied to the functionalization of indomethacin methyl ester, a pharmaceutical agent, $35 \%$ of the desired borylate was isolated (18).

We note that certain aryl chlorides were poorly reactive and returned the majority of the starting material, despite the fact that their reduction potentials suggest that they would be suitable substrates. We reason that in these cases, back electron transfer from intermediate $\left[\mathrm{Ar}-\mathrm{Cl}^{-}\right]$to DCA is sufficiently fast to outcompete scission of the $\mathrm{C}-\mathrm{Cl}$ bond. This hypothesis led us to investigate the corresponding aryl bromides. As expected, the reductive borylation activity was restored. An intramolecular competition experiment revealed that the mesolytic cleavage of a $\mathrm{C}-\mathrm{Br}$ bond is indeed substantially faster than that of a $\mathrm{C}-\mathrm{Cl}$ bond, as 1-chloro-4-bromobenzene (19) was selectively transformed to borodebrominated product 20.

Notably, in addition to haloanisoles, several other electron-rich arenes and hetereoarenes (11-15) were found to be suitable substrates. Some of these aryl halides (e.g., 10, 11, 12, 15) display very negative reduction potentials and represent highly challenging substrates for single electron reduction, ${ }^{8}$ yet were productive under the optimal conditions.

The synthetic utility of this electrophotocatalytic protocol was further expanded to the formation of $\mathrm{C}-\mathrm{Sn}$ and $\mathrm{C}-\mathrm{C}$ bonds by employing different radical trapping agents (Table 3). For example, using hexamethylditin as a coupling partner, we developed metalfree stannylation of aryl halides (22-26). Using $N$-methylpyrrole or 1,4-difluorobenzene, $\mathrm{C}-\mathrm{H}$ arylation products $(\mathbf{2 7}-\mathbf{3 0})$ were isolated in moderate to high yields.

Table 3. Diverse Functionalization of Electrophotocatalytically Generated Aryl Radicals ${ }^{a}$
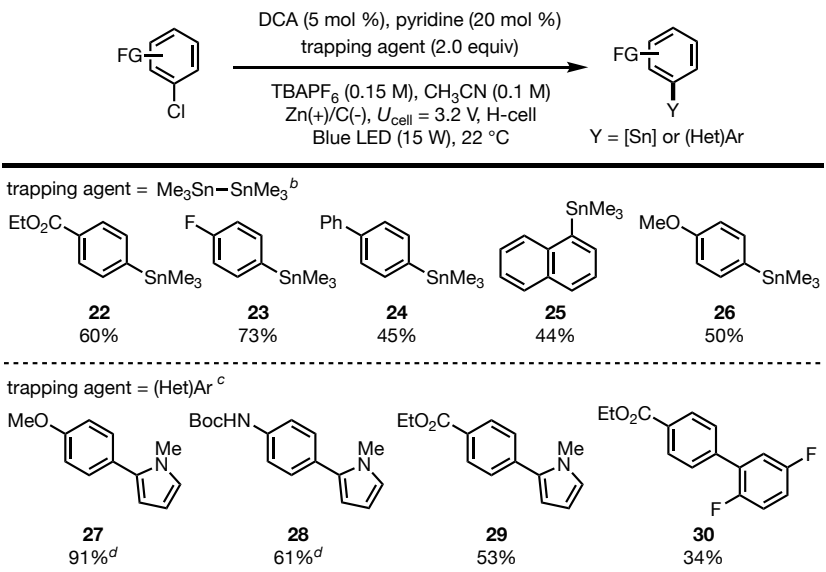

Isolated yields are reported unless otherwise noted. ${ }^{a}$ Cathodic chamber: aryl chloride (0.4 mmol, 1.0 equiv), DCA (5 mol \%), $\mathrm{Sn}_{2} \mathrm{Me}_{6}$ (2.0 equiv), $\mathrm{TBAPF}_{6}(0.15 \mathrm{M}), \mathrm{CH}_{3} \mathrm{CN}(0.1 \mathrm{M})$; anodic chamber: $\operatorname{TBAPF}_{6}(0.15 \mathrm{M})$, $\mathrm{CH}_{3} \mathrm{CN}(0.1 \mathrm{M})$; cell voltage $\left(U_{\text {cell }}\right)=3.2 \mathrm{~V} .{ }^{b}$ Yields determined by ${ }^{1} \mathrm{H}$ NMR. ${ }^{c} 20$ equiv of (hetero)arene was used as the trapping agent. ${ }^{d} 10 \mathrm{~mol} \%$ DCA.

A mechanistic rationale is shown in Figure 2A (pathway A). Thus, the DCA catalyst undergoes cathodic reduction to generate $\mathrm{DCA}^{--}$, which is then photoexcited to generate $\mathrm{DCA}^{-*}$. This highly reducing species can then donate an electron to the $\pi$-system of the aryl halide to furnish intermediate $\mathbf{3 1}$ and to regenerate the DCA catalyst. Aryl halide radical anions $\mathbf{3 1}$ are known to undergo mesolytic cleavage to form aryl radicals $\mathbf{3 2},{ }^{19}$ which can then proceed to the functionalized products.

We also recognized the possibility of a photoinduced reduction of DCA at the cathode to form $\mathrm{DCA}^{--}$(Figure 2A, pathway B), in analogy to König's dual photocatalytic system. However, this pathway is unlikely because DCA $\left(\lambda_{\max }<420 \mathrm{~nm}\right)$ is not efficiently excited by the blue LEDs used in our study. Furthermore, controlled potential electrolysis at different cathodic potentials from 0 to -1.2 $\mathrm{V}$ (Figure $2 \mathrm{~B}$ ) revealed that the onset potential for the reductive borodehalogenation is about $0.4 \mathrm{~V}$ (5\% yield), whereas the optimal reactivity occurs above the thermodynamic reduction potential of DCA $(-0.82 \mathrm{~V})$. The low potential threshold for an outer sphere 
electron transfer event is typically ca. $500 \mathrm{mV}$ below the thermodynamic potential of the reductant. ${ }^{20}$ Meanwhile, because of the highly oxidizing nature of DCA* $(E \sim 2.0 \mathrm{~V}),{ }^{2 \mathrm{~b}}$ an applied potential of $0 \mathrm{~V}$ should have been more than sufficient to reduce DCA*. Thus, these data are fully consistent with the proposed mechanism involving direct electrochemical activation of DCA.

\section{Figure 2. Mechanistic Experiments}

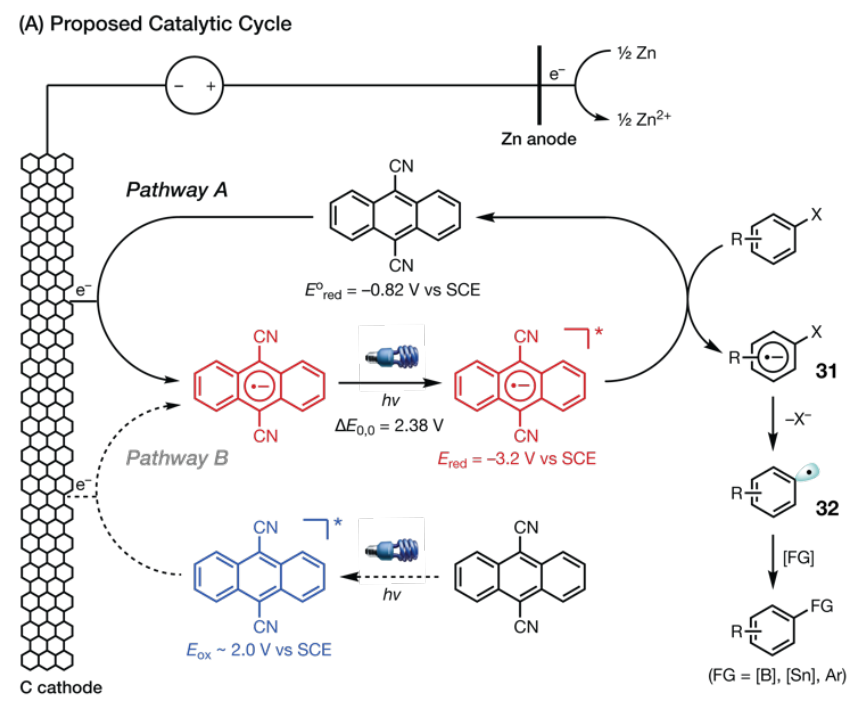

(B) Controlled Potential Electrolysis
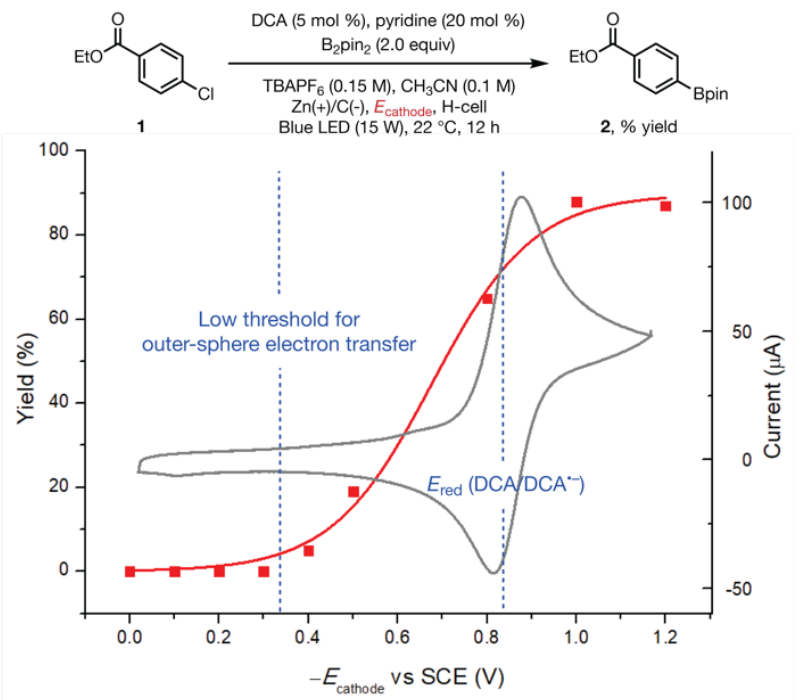

The second alternative pathway entails the formation of an electron-donor acceptor complex between $\mathrm{DCA}^{-}$and the aryl halide substrate, ${ }^{2 b}$ followed by light-promoted inner sphere electron transfer from $\mathrm{DCA}^{-}$to the substrate. However, mixing $\mathrm{DCA}^{-}$with 3 produced no changes to the $\mathrm{UV}$-vis spectrum, which argues against this proposal. ${ }^{2 \mathrm{c}, 21}$

In summary, we report a new electrophotocatalytic strategy to access radical anion species with exceedingly high reducing power through tandem electrochemical activation and photoexcitation. This strategy made possible the chemoselective activation of inert substrates with very negative reduction potentials, which are challenging using existing redox modules that rely solely on photoredox activation. We anticipate that this conceptual advance will be broadly applicable in organic synthesis for reactions that require extreme redox power.
Acknowledgement: Financial support was provided by Cornell University and R35GM127135 (T.H.L.). This study made use of the NMR facility supported by the NSF (CHE-1531632). We thank Dr. Terry $\mathrm{M}^{\mathrm{c}}$ Callum (Cornell University) for helpful discussions.

\section{References:}

1. (a) Zhang, N.; Samanta, S. R.; Rosen, B. M.; Percec, V. Single Electron Transfer in Radical Ion and Radical-Mediated Organic, Materials and Polymer Synthesis. Chem. Rev. 2014, 114, 5848-5958. (b) van der Vlugt, J. I. Radical-Type Reactivity and Catalysis by Single-Electron Transfer to or from Redox-Active Ligands. Chem. Eur. J. 2019, 25, 2651-2662. (c) Plesniak, M. P.; Huang, H.-M.; Procter, D. J. Radical Cascade Reactions Triggered by Single Electron Transfer. Nat. Rev. Chem. 2017, 1, 0077. (d) Ashby, E. C. Single-Electron Transfer, a Major Reaction Pathway in Organic Chemistry. An Answer to Recent Criticisms. Acc. Chem. Res. 1988, 21, 414-421. (e) Zhang, C.; Tang, C.; Jiao, N. Recent Advances in Copper-Catalyzed Dehydrogenative Functionalization via a Single Electron Transfer (SET) Process. Chem. Soc. Rev. 2012, 41, 3464-3484. (f) Broggi, J.; Terme, T.; Vanelle, P. Organic Electron Donors as Powerful Single-Electron Reducing Agents in Organic Synthesis. Angew. Chem., Int. Ed. 2014, 53, 384-413. (g) Roth, H. G.; Romero, N. A.; Nicewicz, D. A. Experimental and Calculated Electrochemical Potentials of Common Organic Molecules for Applications to Single-Electron Redox Chemistry. Synlett 2016, 27, 714-723.

2. For representative reviews on visible-light photocatalysis, see: (a) Skubi, K. L.; Blum, T. R.; Yoon, T. P. Dual Catalysis Strategies in Photochemical Synthesis. Chem. Rev. 2016, 116, 10035-10074. (b) Romero, N. A.; Nicewicz, D. A. Organic Photoredox Catalysis. Chem. Rev. 2016, 116, 10075-10166. (c) Prier, C. K.; Rankic, D. A.; MacMillan, D. W. C. Visible Light Photoredox Catalysis with Transition Metal Complexes: Applications in Organic Synthesis. Chem. Rev. 2013, 113, 5322-5363. (d) Twilton, J.; Le, C.; Zhang, P.; Shaw, M. H.; Evans, R. W.; MacMillan, D. W. C. The Merger of Transition Metal and Photocatalysis. Nat. Rev. Chem. 2017, 1, 0052. (e) Narayanam, J. M. R.; Stephenson, C. R. J. Visible light photoredox catalysis: applications in organic synthesis. Chem. Soc. Rev. 2011, 40, 102-113. (f) Fukuzumi, S.; Ohkubo, K. Organic synthetic transformations using organic dyes as photoredox catalysts. Org. Biomol. Chem. 2014, 12, 60596071.

3. For representative reviews on electrochemistry, see: (a) Yan, M.; Kawamata, Y.; Baran, P. S. Synthetic Organic Electrochemical Methods Since 2000: On the Verge of a Renaissance. Chem. Rev. 2017, 117, 13230-13319. (b) Sauer, G. S.; Lin, S. An Electrocatalytic Approach to the Radical Difunctionalization of Alkenes. ACS Catal. 2018, 8, 5175-5187. (c) Meyer, T. H.; Finger, L. H.; Gandeepan, P.; Ackermann, L. Resource Economy by Metallaelectrocatalysis: Merging Electrochemistry and $\mathrm{C}-\mathrm{H}$ Activation. Trends in Chem. 2019, 1, 63-76. (d) Moeller, K. D. Using Physical Organic Chemistry To Shape the Course of Electrochemical Reactions. Chem. Rev. 2018, 118, 4817-4833. (e) Waldvogel, S. R.; Lips, S.; Selt, M.; Riehl, B.; Kampf, C. J. Electrochemical Arylation Reaction. Chem. Rev. 2018, 118, 6706-6765. (f) Nutting, J. E.; Rafiee, M.; Stahl, S. S. Tetramethylpiperidine N-Oxyl (TEMPO), Phthalimide N-Oxyl (PINO), and Related N-Oxyl Species: Electrochemical Properties and Their Use in Electrocatalytic Reactions. Chem. Rev. 2018, 118, 4834-4885. (g) Tang, S.; Liu, Y.; Lei, A. Electrochemical Oxidative Cross-coupling with Hydrogen Evolution: A Green and Sustainable Way for Bond Formation. Chem 2018, 4, 27-45.

4. (a) Peters, B. K.; Rodriguez, K. X.; Reisberg, S. H.; Beil, S. B.; Hickey, D. P.; Kawamata, Y.; Collins, M.; Starr, J.; Chen, L.; Udyavara, S.; Klunder, K.; Gorey, T. J.; Anderson, S. L.; Neurock, M.; Minteer, S. D.; Baran, P. S. Scalable and Safe Synthetic Organic Electroreduction Inspired by Li-Ion Battery Chemistry. Science 2019, 363, 838-845. (b) Perkins, R. J.; Pedro, D. J.; Hansen, E. C. Electrochemical Nickel Catalysis for $\mathrm{Sp}^{2}-\mathrm{Sp}^{3}$ Cross- 
Electrophile Coupling Reactions of Unactivated Alkyl Halides. Org. Lett. 2017, 19, 3755-3758. (c) Sun, G.; Ren, S.; Zhu, X.; Huang, M.; Wan, Y. Direct Arylation of Pyrroles via Indirect Electroreductive $\mathrm{C}-\mathrm{H}$ Functionalization Using Perylene Bisimide as an Electron-Transfer Mediator. Org. Lett. 2016, 18, 544-547. (d) Edinger, C.; Waldvogel, S. R. Electrochemical Deoxygenation of Aromatic Amides and Sulfoxides. Eur. J. Org. Chem. 2014, 2014, 5144-5148.

5. Recent examples of combining electrochemistry and photochemistry for organic synthesis: (a) Wang, F.; Stahl, S. S. Merging Photochemistry with Electrochemistry: Functional-Group Tolerant Electrochemical Amination of $\mathrm{C}\left(\mathrm{sp}^{3}\right)-\mathrm{H}$ Bonds. Angew. Chem., Int. Ed. 2019, 58, 6385-6390. (b) Zhang, L.; Liardet, L.; Luo, J.; Ren, D.; Grätzel, M.; Hu, X. Photoelectrocatalytic Arene C-H Amination. Nat. Catal. 2019, 2, 366-373. (c) Yan, H.; Hou, Z.W.; Xu, H.-C. Photoelectrochemical C-H Alkylation of Heteroarenes with Organotrifluoroborates. Angew. Chem., Int. Ed. 2019, 58, 4592-4595.

6. Huang, H.; Strater, Z. M.; Rauch, M.; Shee, J.; Sisto, T. J.; Nuckolls, C.; Lambert, T. H. Electrophotocatalysis with a Trisaminocyclopropenium Radical Dication. Angew. Chem., Int. Ed. 2019, $58,13318-13322$.

7. (a) Lund, H.; Carlsson, H. S. Photochemistry of Radical Ions. Acta Chem. Scand. B. 1978, 32, 505-509. (b) Carlsson, H. S.; Lund, H. Photochemistry of Radical Ions. II. Influence of Thermal Convection and Photoexcitation on Voltammetric Curves. Acta Chem. Scand. B. 1980, 34, 409-412. (c) Fox, M. A. The Photoexcited States of Organic Anions. Chem. Rev. 1979, 79, 253-273.

8. (a) Ghosh, I.; Ghosh, T.; Bardagi, J. I.; König, B. Reduction of Aryl Halides by Consecutive Visible Light-Induced Electron Transfer Processes. Science 2014, 346, 725-728. (b) Ghosh, I.; Marzo, L.; Das, A.; Shaikh, R.; König, B. Visible Light Mediated Photoredox Catalytic Arylation Reactions. Acc. Chem. Res. 2016, 49, 1566-1577. (c) Ghosh, I.; König, B. Chromoselective Photocatalysis: Controlled Bond Activation through Light-Color Regulation of Redox Potentials. Angew. Chem., Int. Ed. 2016, 55, 7676-7679. (d) Bardagi, J. I.; Ghosh, I.; Schmalzbauer, M.; Ghosh, T.; König, B. Anthraquinones as Photoredox Catalysts for the Reductive Activation of Aryl Halides. Eur. J. Org. Chem. 2018, 2018, 34-40. (e) Neumeier, M.; Sampedro, D.; Májek, M.; de la Peña O'Shea, V. A.; Jacobi von Wangelin, A.; Pérez-Ruiz, R. Dichromatic Photocatalytic Substitutions of Aryl Halides with a Small Organic Dye. Chem. Eur. J. 2018, 24, 105-108.

9. Eriksen, J.; Lund, H.; Nyvad. A. I. Electron-Transfer Fluorescence Quenching of Radical Ions. Acta Chem. Scand. B. 1983, 37, 459-466.

10. The reduction potential of radical anion photocatalyst was estimated by Rehm-Weller formalism. For a reference, see: Rehm, D.; Weller, A. Kinetics of Fluorescence Quenching by Electron and H-Atom Transfer. Isr. J. Chem. 1970, 8, 259-262.

11. For representative recent examples, see: (a) Nguyen, J. D.; D'Amato, E. M.; Narayanam, J. M. R.; Stephenson, C. R. J. Engaging Unactivated Alkyl, Alkenyl and Aryl Iodides in VisibleLight-Mediated Free Radical Reactions. Nat. Chem. 2012, 4, 854-859. (b) Devery, J. J.; Nguyen, J. D.; Dai, C.; Stephenson, C. R. J. Light-Mediated Reductive Debromination of Unactivated Alkyl and Aryl Bromides. ACS Catal. 2016, 6, 5962-5967. (c) Boyington, A. J.; Riu, M.-L. Y.; Jui, N. T. Anti-Markovnikov Hydroarylation of Unactivated Olefins via Pyridyl Radical Intermediates. J. Am. Chem. Soc. 2017, 139, 6582-6585. (d) Seath, C. P.;
Vogt, D. B.; Xu, Z.; Boyington, A. J.; Jui, N. T. Radical Hydroarylation of Functionalized Olefins and Mechanistic Investigation of Photocatalytic Pyridyl Radical Reactions. J. Am. Chem. Soc. 2018, 140, 15525-15534. (e) Aycock, R. A.; Vogt, D. B.; Jui, N. T. A Practical and Scalable System for Heteroaryl Amino Acid Synthesis. Chem. Sci. 2017, 8, 7998-8003.

12. Costentin, C.; Robert, M.; Savéant, J.-M. Fragmentation of Aryl Halide $\pi$ Anion Radicals. Bending of the Cleaving Bond and Activation vs Driving Force Relationships. J. Am. Chem. Soc. 2004, 126, 16051-16057.

13. (a) Zhang, L.; Jiao, L. Visible-Light-Induced Organocatalytic Borylation of Aryl Chlorides. J. Am. Chem. Soc. 2019, 141, 9124-9128. (b) Chen, K.; Cheung, M. S.; Lin, Z.; Li, P., MetalFree Borylation of Electron-Rich Aryl (Pseudo)halides Under Continuous-Flow Photolytic Conditions. Org. Chem. Front. 2016, 3, 875-879. (c) Mfuh, A. M.; Nguyen, V. T.; Chhetri, B.; Burch, J. E.; Doyle, J. D.; Nesterov, V. N.; Arman, H. D.; Larionov, O. V. Additive- and Metal-Free, Predictably 1,2- and 1,3-Regioselective, Photoinduced Dual C-H/C-X Borylation of Haloarenes. $J$. Am. Chem. Soc. 2016, 138, 8408-8411. (d) Mfuh, A. M.; Doyle, J. D.; Chhetri, B.; Arman, H. D.; Larionov, O. V. Scalable, Metaland Additive-Free, Photoinduced Borylation of Haloarenes and Quaternary Arylammonium Salts. J. Am. Chem. Soc. 2016, 138, 2985-2988.

14. Zhang, L.; Jiao, L. Pyridine-Catalyzed Radical Borylation of Aryl Halides. J. Am. Chem. Soc. 2017, 139, 607-610.

15. Haimerl, J.; Ghosh, I.; König, B.; Vogelsang, J.; Lupton, J. M. Single-Molecule Photoredox Catalysis. Chem. Sci. 2019, 10, 681-687.

16. Ragnarsson, U.; Grehn, L.; Maia, H. L. S.; Monteiro, L. S. Enhancing Reductive Cleavage of Aromatic Carboxamides. Org. Lett. 2001, 3, 2021-2023.

17. Ishiyama, T.; Murata, M.; Miyaura, N. Palladium(0)-Catalyzed Cross-Coupling Reaction of Alkoxydiboron with Haloarenes: A Direct Procedure for Arylboronic Esters. J. Org. Chem. 1995, 60, 7508-7510.

18. For example, aminoesters have been used as ligands for Pd catalysis: Lu, Y.; Wang, D.-H.; Engle, K. M.; Yu, J.-Q. Pd(II)Catalyzed Hydroxyl-Directed C-H Olefination Enabled by Monoprotected Amino Acid Ligands. J. Am. Chem. Soc. 2010, 132, 5916-5921.

19. Takeda, N.; Poliakov, P. V.; Cook, A. R.; Miller, J. R. Faster Dissociation: Measured Rates and Computed Effects on Barriers in Aryl Halide Radical Anions. J. Am. Chem. Soc. 2004, 126, 4301-4309.

20. (a) Francke, R.; Little, R. D. Redox Catalysis in Organic Electrosynthesis: Basic Principles and Recent Developments. Chem. Soc. Rev. 2014, 43, 2492-2521. (b) Steckhan, E. Indirect Electroorganic Syntheses-A Modern Chapter of Organic Electrochemistry [New Synthetic Methods (59)]. Angew. Chem., Int. Ed. Engl. 1986, 25, 683-701.

21. (a) Arias-Rotondo, D. M.; McCusker, J. K. The Photophysics of Photoredox Catalysis: A Roadmap for Catalyst Design. Chem. Soc. Rev. 2016, 45, 5803-5820. (b) Fukuzumi, S.; Kochi, J. K. Nature of Electrophiles and Electron Acceptors. Comparison of Their Molecular Complexes with Aromatic Donors. J. Org. Chem. 1981, 46, 4116-4126. 
Other files

TOC.pdf (710.66 KiB)

view on ChemRxiv - download file 